\title{
Food Waste Loss Trend Index (FWLTI), A New Tool to Enable Management Decisions
}

http://doi.org/10.21272/bel.5(3).47-60.2021

János Zachár, ORCID: https://orcid.org/0000-0002-3156-4752

Doctoral Candidate, MATE (Hungarian University of Agriculture and Life Sciences), Kaposvár Campus, Doctoral School in Management and Organizational Sciences, Hungary

\begin{abstract}
The main purpose of this research is to work out a new, innovative tool to describe trends of food waste and loss (FWL) in the food industry. The result can help evaluate efforts for lowering wastes. FWL prevention recently gained much attention and priority among governments and international organizations as a major means to achieve global food security and sustainability; this led to the very ambitious UN goal SDG 12.3, which aims to halve global food losses by 2030. It is an ethical obligation to achieve SDGs by 2030. It is not declared in law and is not required for profitability in the food industry. A new tool is proposed to evaluate efforts to halve food losses in this article, which one may be used in leadership easily and effectively. At first, FWL definitions were analyzed to get a clear picture of the content of FWL data sourced from FAOSTAT and EUROSTAT. These definitions were compared with others from different sources. It is concluded that we have so many different definitions for FWL because of the difference in the purpose of data collecting. The most justified definition - often newly created - is used in each case. FWL data received from FAOSTAT and EUROSTAT in the period of 2010 - 2018 were compared to find the correlation. It is inverse and very weak, so they are not comparable; they must be evaluated separately. The trend of the FWL data is increasing and is not significant on level 95\% in EUROSTAT, and decreasing and important on level 95\% in FAOSTAT, from 2010 to 2018. FWL data from EUROSTAT are in moderate correlation with GDP and HDI. A new index, Food Waste Loss Trend Index (FWLTI), was created to evaluate FWL in EU member states and analyzed them with cluster analyses and scatterplots. There was no connection among the EU28 member states with FWLTI, so every member state is an individual case; there are no standard rules for FLW generation.
\end{abstract}

Keywords: Food Waste and Loss, Definition Analysis, FAOSTAT and EUROSTAT Data Comparison, Trend Evaluation, Correlation with GDP and HDI, EU28, Tool for Leadership.

JEL Classification: Q5, Q53.

Cite as: Zachár, J. (2021). Food Waste Loss Trend Index (FWLTI), A New Tool to Enable Management Decisions. Business Ethics and Leadership, 5(3), 47-60. http://doi.org/10.21272/bel.5(3).47-60.2021.

Received: 10 July $2021 \quad$ Accepted: 02 September $2021 \quad$ Published: 13 September 2021

Copyright: (C) 2021 by the author. Licensee Sumy State University, Ukraine. This article is an open access article distributed under the terms and conditions of the Creative Commons Attribution (CC BY) license (https://creativecommons.org/licenses/by/4.0/).

\section{Introduction}

This article was written as part of doctoral theses, answering the research question "How much food waste is generated in the food industry in reality, what are the main reasons for food waste, and how can we minimize it?". Answers to research question were published in three parts: results on global (world), regional (EU28), and local (Hungary) levels. This publication is about the research and findings in the EU28.

The aim of this paper is:

to analyze FWL definitions to get a clear picture about the content of FWL data sourced from FAOSTAT and EUROSTAT, and to compare these definitions with others from different sources,

to compare FWL data received from FAOSTAT and EUROSTAT from 2010 to 2018, and to find correlations,

to calculate trends of FWL generation and to test for significance of changes,

$>$ to calculate correlation with indexes (GDP and HDI),

to create new indexes for FWL in EU member states and analyze them with cluster analyses and scatterplot.

1.1 General Situation. According to the Food and Agriculture Organization of the United Nations (FAO), up to one-third of all food is lost or wasted worldwide throughout the supply chain. It corresponds to about 1.3 
billion tons per year and represents the waste of resources, water, energy, land, and other inputs used for producing that food, including labour (Blakeney, 2019). FWL prevention recently gained a lot of attention and priority among governments and international organizations as a major means to achieve global food security and sustainability; this led to the very ambitious UN goal SDG 12.3, which aims to halve global food losses by 2030. Resolution adopted by the General Assembly on 25 September 2015 (United Nations, 2015). In EU28, the sectors contributing the most to FWL are households (47 million tonnes \pm 4 million tonnes) and the processing sector (17 million tonnes \pm 13 million tonnes). These two sectors account for $72 \%$ of EU food waste, although there is considerable uncertainty around the estimate for the processing sector. In addition, and as previously mentioned, the uncertainties for the production sector are probably underestimated. Of the remaining 28 percent of FWL, 11 million tons (12\%) come from the foodservice, 9 million tons (10\%) come from production, and 5 million tons (5\%) come from wholesale and retail (Stenmarck et al., 2016).

For Europe, different estimates are highly uncertain, mainly since different methods exist for quantifying FWL, different databases are used for the calculation (e.g., FAOSTAT and EUROSTAT), and there is a lack of harmonization in the nomenclature (Cristóbal, Castellani, Manfredi, \& Sala, 2018), (Kasza, Szabó-Bódi, Lakner, \& Izsó, 2019), (Bräutigam, Jörissen, \& Priefer, 2014). Thanks to the recent Circular Economy (CE) package (European Comission, 2020), food waste prevention has gained prominence in the European political debate. The CE Action Plan (European Comission, 2015) included food waste within the so-called "priority areas,", i.e., areas that should be carefully considered to strengthen the circularity of the European economy.

1.2 Definitions of $\boldsymbol{F W L}$. FWL definitions and system boundaries need to be carefully selected and communicated transparently, as the chosen definition and system boundaries will impact the results and conclusions (Hartikainen, Mogensen, Svanes, \& Franke, 2018). They are not universally agreed upon, which makes studying and quantifying FWL difficult. Different categorizations are generated based on what materials are included, the means of production, and the management approaches (Thyberg \& Tonjes, 2016). Although some FWL definitions have been developed regarding major societal issues, there are still numerous inconsistencies and ambiguities. Some choices have not been justified. Most studies have overlooked the use of non-consumed food products. Regardless of their use or non-use, studies have presumed that non-consumed food was FWL (Chaboud \& Daviron, 2017).

1.3 Inconsistency in Statistical Data. The reported waste statistics are highly uncertain, mostly because different methods exist for quantifying FWL, different databases are used for the calculation (e.g., FAOSTAT and EUROSTAT), and there is a lack of harmonization in the nomenclature (Cristóbal et al., 2018). On the other hand, as Bräutigam et al. concluded, the comparison of the data reveals that the results on FWL generation in the EU-28 differ significantly, depending on the data sources chosen and the assumptions made. EUROSTAT's waste statistics are not yet sufficient for providing an insight into the extent of food waste generation in the EU because they do not explicitly cover this category (Bräutigam et al., 2014), and differences between the waste data are not always fully interpretable (Corrado \& Sala, 2018).

This inconsistency was found not only in Europe but in Australia, too. The results show substantial inconsistencies between the available datasets and methodologies used to employ them to characterize the total Australian FWL across sectors and food types (Reutter, Lant, \& Lane, 2017). It must be remarked that the possibility of inconsistency in food waste data was not mentioned when food waste generation was analysed in Japan (Fujii \& Kondo, 2018). The FAO issue used data from FAOSTAT, too, to build up a model to identify food waste quantity (Blakeney, 2019). In the future, the material flow may be investigated for suitability to estimate real FWL. In this process, the standard "ISO 14052:2017 Environmental management - Material flow cost accounting - Guidance for practical implementation in a supply chain" could be considered, guiding the practical implementation of material flow cost accounting (MFCA) in a supply chain. Perhaps the new Commission Implementing Decision (European Comission, 2019) laying down a format for reporting the data on food waste will lead to more consistent food waste data. The European Union permits (European Parliament, 2002) to collect data with surveys, administrative or other sources, such as the reporting obligations under Community legislation on waste management, statistical estimation procedures on the basis of samples or waste-related estimators, or their combination. It is a remarkable source of mistakes. Annex I of regulation (EC) No 2150/2002 (European Parliament, 2002) contains the EWC codes:

09.1 Animal and mixed food waste

09.2 Vegetal wastes

We can read in Annex III of the regulation (EC) No 2150/2002 that EWC 09.1 contains types of waste as "sludge from washing and cleaning" and "wastes from preserving agents". EWC 09.2 contains such types of 
waste as "wastes from forestry", sludge from washing, cleaning, peeling, centrifuging and separation, etc. The "Guidance on classification of waste according to EWC-Stat categories - Supplement to the Manual for the Implementation of the Regulation (EC) No 2150/2002 on Waste Statistics, Version 2, December 2010" precisely explains it (EUROSTAT, 2010). There is an essential difference in food waste classification, given by regulation (EC) No 2150/2002, and food waste definition, given by directive No. 2008/98/EC (European Parliament, 2008). The waste statistics are based on Regulation (EC) No 2150/2002 on Waste Statistics in EUROSTAT, so, in this publication, especially based on the Guidance, as mentioned in the previous paragraph, W091+W092 is understood as FWL from field to households.

1.4 Indexes to Evaluate Policies. Z. Irani et al. wrote in their article that they sought to provide policymakers with a means to evaluate new and existing policies, whilst also offering a practical basis through which food chains can be made more resilient through the consideration of management practices and policy decisions (Irani et al., 2018). K. Schanes et al. concluded that FWL is related to the policy (Schanes, Dobernig, \& Gözet, 2018). C. Reynolds et al. give a novel and important addition to the researchers', policymakers', and practitioners' tool kit. They found that most current interventions achieve only a 5-20\% reduction in food waste. But it does not give the possibility to evaluate the efficiency of this tool kit (Reynolds et al., 2019). Article of T.C. Kinnaman evaluates policies, but it is expressed only in natural quantities $(\mathrm{kg})$. It does not show tendencies or trends as an index (Kinnaman, 2006). So, the purpose of this work is to recommend an index as tool kit to evaluate FWL lowering efforts.

\section{Material and Methods}

\subsection{Overview of Definitions}

\subsubsection{FAO (Blakeney, 2019)}

"Food" waste or loss is measured only for products that are intended for human consumption, excluding feed and parts of products that are not edible. Per definition, food losses or waste are the masses of food lost or wasted in the part of food chains leading to "edible products going to human consumption". Therefore, food that was originally meant for human consumption but which gets out of the human food chain is considered food loss or waste even if directed to non-food use (feed, bioenergy, etc.). This approach distinguishes "planned" non-food uses to "unplanned" non-food uses, which are hereby accounted under losses.

\subsubsection{European Parliament and European Council (European Parliament, 2008)}

bio-waste: biodegradable garden and park waste, food and kitchen waste from households, offices, restaurants, wholesale, canteens, caterers and retail premises and comparable waste from food processing plants;

D food waste: all food (any substance or product, whether processed, partially processed or unprocessed, intended to be, or reasonably expected to be ingested by humans; drink, chewing gum, including water, intentionally incorporated into the food during its manufacturing, preparation or treatment) that has become waste.

The regulation (EC) No 2150/2002 on waste statistics, mentioned above, contains a classification, but does not contain definitions.

\subsubsection{WRAP (The Waste and Resources Action Programme) (Hanson et al., 2016)}

Food "loss and waste" is removed from the food supply chain, only associated inedible parts, or both food and associated inedible parts removed from the food supply chain. The FWL Standard does not precisely specify which set of destinations comprises "loss and waste." Instead, it gives a globally consistent and applicable definition of the possible destinations for food and/or associated inedible parts removed from the food supply chain.

\subsubsection{FUSIONS (Food Use for Social Innovation by Optimising Waste Prevention Strategies) project (Stenmarck et al., 2016)}

Food waste: Fractions of "food and inedible parts of food removed from the food supply chain" to be recovered or disposed of (including - composted, crops ploughed in/not harvested, anaerobic digestion, bioenergy production, co-generation, incineration, disposal to sewer, landfill or discarded to sea).

2.1.5. U.S. Environmental Protection Agency's (EPA). Food waste estimate is described as "The amount of food going to landfills from residences, commercial establishments (e.g., grocery stores and restaurants), institutional sources (e.g., school cafeterias), and industrial sources (e.g., factory lunchrooms). Pre-consumer 
food generated during the manufacturing and packaging of food products is not included in EPA's food waste estimates" (Bellemare, Çakir, Peterson, Novak, \& Rudi, 2017).

2.2 Comparison of These Five Definitions. FAO and the EU take into consideration "products that are intended for human consumption (expected to be ingested by humans)". FUSION and WRAP also include inedible parts. EPA identifies only "[food] going to landfills from residences, commercial establishments". See Table 2.

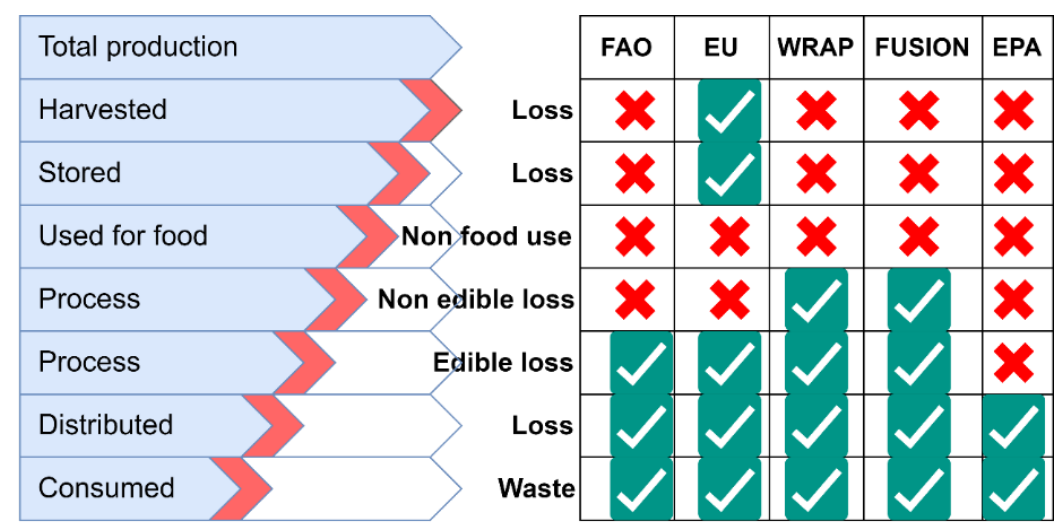

Figure. 1. Content of FWL Definitions

Source: Compiled by the author

Usually, scientific articles use one of the definitions written above. They rarely use their definitions. For example, Thyberg and Tonjes give another explanation to FW and FL. It was made based on generation drivers, showing the sectors involved (Thyberg \& Tonjes, 2016). Chaboud and Daviron mentioned that overconsumption is FL, too (Chaboud \& Daviron, 2017). Bellemare and his colleagues analyzed the gap in definitions discussed above. They suggest that "food waste" is the difference between the amount of food produced and the sum of all food employed in any productive use, whether food or non-food (Bellemare et al., 2017). This definition is quite close to material flow. The standard "ISO 22000:2018 Food safety management systems Requirements for any organization in the food chain" does not mention waste. The standardization gives economic benefit (Radauer, 2020), and in the same way, the standard definition of FWL can lead to better scientific results. Many Best Available Techniques (BAT) were published based on Directive 2010/75/EU on industrial emissions (integrated pollution prevention and control), but not one concerning food waste. It seems that a new standard (maybe only on FWL) can fix the gap in definitions. This solution may be optimal or the best, but it may not be perfect because the gap is too deep. We can conclude that we have so many different definitions for FWL because of the difference in the purpose of data collecting. The most justified definition - often newly created - is used in each case.

\subsection{Data Collecting and Processing}

2.3.1 Total Consumption Chain Waste (TCCW). Data called "Generation of waste-by-waste category, hazardousness and NACE Rev. 2 activity [ENV_WASGEN\$DEFAULTVIEW]" was downloaded from Eurostat, which were extracted on 04/12/2020 17:35:57 from [ESTAT], and last updated on 22/10/2020 23:00. Sheet 28 "Animal and mixed food waste" (W09.1) and Sheet 29 "Vegetal wastes" (W09.2) were taken from dataset. They were summarized and mentioned in this article as Total Consumption Chain Waste (TCCW). We must pay attention to the header of the sheets, where it is written in both cases: Classification of economic activities (NACE Rev.2) - All NACE activities plus households. As written in the previous paragraph.

2.3.2 Food Supply Chain Loss (FSCL). FAOSTAT data were also downloaded, as Food Balances for Europe on 08/12/2020. Data were in csv file, which was saved last on 04/02/2020. This file contains data for 20142017, but the TCCW are from 2010, 2012, 2014, 2016, and 2018. On the same day, "Food Balances (old methodology and population)" were downloaded in csv file, which one was saved last time on 15/12/2016. There is code 5123 in this file, but it is called "waste", while later the code 5123 is called "losses". The reason for using these two different words is the change of statistic methodology by FAOSTAT. The changes are well described in the document "New Food Balances - Description of utilization variables" (FAO, n.d.). So, the "Loss" in FAOSTAT data most closely aligns with "post-harvest/post-slaughter loss", representing those quantities of food that leave the production/supply chain at any stage from post-harvest up to the retail level (the level of the supply chain at which "food availability" is defined). Countries are increasingly attempting to measure or estimate loss as part of their overall agricultural statistical programs. FAO recommends using targeted surveys to measure loss for them. It may include surveying the loss in on-farm operations and storage, 
the loss in warehouses or collection points, the loss in transportation and the loss in public storage. For most countries, at least some data on loss in specific supply chain segments is most likely available outside of official sources, as loss incurs real-world economic costs for supply chain actors. There are two approaches: Suggested approaches, where some historical data is available, it may be optimal to estimate the loss through a regression approach so that the loss is modeled as a function of certain other variables. An alternative approach is that country-level compilers can calculate their loss using official data from countries that report the loss. It is done by estimating the relationship between officially reported production levels and officially reported loss using what is called a hierarchical linear model (Gelman \& Hill, 2008).

"Waste" was taken from 2010 and 2012, and at preliminary evaluation was concluded: Cyprus is missing from the European data, so the author downloaded separately to summarize data from EU member states, and Data from 2018 were uploaded to FAOSTAT. These data were downloaded from FAOSTAT on 31/01/2021.

The next conclusion was that losses are doubled in FAOSTAT data from 2014 to 2017, with two different flags: A (Aggregated) and S (Standardized). Data with flag S were taken into consideration only. These data, reached from FAOSTAT are named later in this article as Food Supply Chain Loss (FSCL).

2.3.3 Data Collecting Summary. It may be concluded that based on the difference in data collecting methods, the FAOSTAT and EUROSTAT the TCCW and FSCL are not comparable; they must be evaluated separately. It could not be said that FSCL + waste in households is equal to TCCW (W091+092 in EUROSTAT), which may be expressed in the formula:

$$
\text { TCCW } \neq \text { FSCL + households }
$$

TCCW and FSCL for 2010, 2012, 2014, 2016 and 2018 years are given in Table 1. To calculate the "per capita" amounts of the TCCW the population data from FAOSTAT was used.

Table 1. TCCW and FSCL in the EU28 and other European Countries in 2010-2018

\begin{tabular}{|c|c|c|c|c|c|c|c|c|c|c|c|}
\hline \multirow{2}{*}{ Country } & \multirow[t]{2}{*}{ Year } & \multicolumn{2}{|c|}{2010} & \multicolumn{2}{|c|}{2012} & \multicolumn{2}{|c|}{2014} & \multicolumn{2}{|c|}{2016} & \multicolumn{2}{|c|}{2018} \\
\hline & & TCCW & FSCL & TCCW & FSCL & TCCW & FSCL & TCCW & FSCL & TCCW & FSCL \\
\hline \multirow{3}{*}{ Austria } & population & \multicolumn{2}{|c|}{8402} & \multicolumn{2}{|c|}{8464} & \multicolumn{2}{|c|}{8615} & \multicolumn{2}{|c|}{8747} & \multicolumn{2}{|c|}{8891} \\
\hline & losses & 1345 & 908 & 1828 & 904 & 1833 & 785 & 2014 & 725 & 2225 & 698 \\
\hline & Losses/capita & 160 & 108 & 216 & 107 & 213 & 91 & 230 & 83 & 250 & 79 \\
\hline \multirow{3}{*}{ Belgium } & population & \multicolumn{2}{|c|}{10941} & \multicolumn{2}{|c|}{11060} & \multicolumn{2}{|c|}{11221} & \multicolumn{2}{|c|}{11354} & \multicolumn{2}{|c|}{11482} \\
\hline & losses & 4736 & 1422 & 4941 & 1116 & 5626 & 758 & 6608 & 672 & 8749 & 645 \\
\hline & Losses/capita & 433 & 130 & 447 & 101 & 501 & 68 & 582 & 59 & 762 & 56 \\
\hline \multirow{3}{*}{ Bulgaria } & population & \multicolumn{2}{|c|}{7389} & \multicolumn{2}{|c|}{7278} & \multicolumn{2}{|c|}{7246} & \multicolumn{2}{|c|}{7152} & \multicolumn{2}{|c|}{7052} \\
\hline & losses & 261 & 1521 & 623 & 1565 & 408 & 742 & 561 & 738 & 364 & 629 \\
\hline & Losses/capita & 35 & 206 & 86 & 215 & 56 & 102 & 78 & 103 & 52 & 89 \\
\hline \multirow{3}{*}{ Croatia } & population & & & & & & & 42 & & $\overline{41}$ & \\
\hline & losses & 111 & 289 & 73 & 233 & 148 & 343 & 134 & 400 & 132 & 315 \\
\hline & Losses/capita & 26 & 67 & 17 & 54 & 35 & 81 & 32 & 95 & 32 & 76 \\
\hline & population & & & 10 & & & & 10 & & 10 & \\
\hline Czech Republic & losses & 450 & 367 & 443 & 539 & 583 & 605 & 772 & 598 & 818 & 454 \\
\hline & Losses/capita & 43 & 35 & 42 & 51 & 55 & 57 & 73 & 56 & 77 & 43 \\
\hline & population & & & & & & & $\overline{11}$ & & $\overline{11}$ & \\
\hline Cyprus & losses & 88 & 49 & 47 & 50 & 64 & 54 & 72 & 55 & 79 & 60 \\
\hline & Losses/capita & 80 & 44 & 41 & 44 & 56 & 47 & 61 & 47 & 67 & 50 \\
\hline & population & & & & & & & 57 & & 57 & \\
\hline Denmark & losses & 972 & 1057 & 852 & 1182 & 1016 & 632 & 1096 & 631 & 1329 & 605 \\
\hline & Losses/capita & 175 & 190 & 152 & 211 & 179 & 112 & 192 & 110 & 231 & 105 \\
\hline & population & & & & & & & $\overline{13}$ & & $\overline{13}$ & \\
\hline Estonia & losses & 210 & 38 & 37 & 36 & 61 & 21 & 99 & 38 & 117 & 35 \\
\hline & Losses/capita & 162 & 29 & 29 & 28 & 47 & 16 & 75 & 29 & 89 & 26 \\
\hline & population & & & & & & & 54 & & 55 & \\
\hline Inland & losses & 878 & 73 & 965 & 78 & 997 & 377 & 1016 & 340 & 1039 & 249 \\
\hline & Losses/capita & 163 & 14 & 178 & 14 & 183 & 69 & 185 & 62 & 188 & 45 \\
\hline & population & & & 63 & & 64 & & 64 & & 66 & \\
\hline France & losses & 9106 & 6572 & 10981 & 6211 & 11004 & 5453 & 10888 & 4955 & 11560 & 6636 \\
\hline & Losses/capita & 144 & 104 & 172 & 97 & 171 & 85 & 168 & 77 & 173 & 99 \\
\hline & population & & & 82 & & & & 82 & & 83 & 24 \\
\hline Germany & losses & 11957 & 6991 & 12658 & 7469 & 13785 & 4976 & 14651 & 5219 & 14149 & 4822 \\
\hline & Losses/capita & 144 & 84 & 153 & 90 & 169 & 61 & 178 & 63 & 170 & 58 \\
\hline
\end{tabular}


Table 1 (cont.). TCCW and FSCL in the EU28 and other European Countries in 2010-2018

\begin{tabular}{|c|c|c|c|c|c|c|c|c|c|c|c|}
\hline \multirow{3}{*}{ Greece } & population & \multicolumn{2}{|c|}{11110} & \multicolumn{2}{|c|}{11125} & \multicolumn{2}{|c|}{10701} & \multicolumn{2}{|c|}{10615} & \multicolumn{2}{|c|}{10522} \\
\hline & losses & 433 & 2005 & 484 & 1975 & 568 & 1187 & 969 & 1236 & 812 & 1195 \\
\hline & Losses/capita & 39 & 180 & 44 & 178 & 53 & 111 & 91 & 116 & 77 & 114 \\
\hline \multirow{3}{*}{ Hungary } & population & \multicolumn{2}{|c|}{10015} & \multicolumn{2}{|c|}{9976} & \multicolumn{2}{|c|}{9805} & \multicolumn{2}{|c|}{9753} & \multicolumn{2}{|c|}{9707} \\
\hline & losses & 630 & 922 & 613 & 752 & 304 & 462 & 341 & 403 & 431 & 600 \\
\hline & Losses/capita & 63 & 92 & 61 & 75 & 31 & 47 & 35 & 41 & 44 & 62 \\
\hline \multirow{3}{*}{ Ireland } & population & \multicolumn{2}{|c|}{4468} & \multicolumn{2}{|c|}{4576} & \multicolumn{2}{|c|}{4627} & & & & \\
\hline & losses & 1846 & 341 & 1115 & 431 & 543 & 160 & 1136 & 159 & 1144 & 137 \\
\hline & Losses/capita & 413 & 76 & 244 & 94 & 117 & 35 & 242 & 34 & 237 & 28 \\
\hline & population & & & & & & & & & & \\
\hline Italy & losses & 9068 & 4189 & 5697 & 3733 & 6840 & 1902 & 7768 & 1937 & 8390 & 1691 \\
\hline & Losses/capita & 150 & 69 & 94 & 61 & 113 & 31 & 128 & 32 & 138 & 28 \\
\hline & population & & & & & & & & & & \\
\hline Latvia & losse & 166 & 96 & 137 & 110 & 105 & 44 & 143 & 55 & 258 & 67 \\
\hline & Losses/capita & 80 & 46 & 67 & 53 & 52 & 22 & 73 & 28 & 134 & 35 \\
\hline & population & & & & & & & & & & \\
\hline Lithuania & loss & 392 & 247 & 468 & 347 & 514 & 239 & 403 & 309 & 401 & 270 \\
\hline & Losses/capita & 128 & 81 & 155 & 115 & 173 & 80 & 139 & 107 & 143 & 96 \\
\hline & population & & & & & & & & & & \\
\hline Luxembourg & loss & 88 & 18 & 84 & 19 & 95 & 14 & 125 & 11 & 129 & 10 \\
\hline & Losses/capita & 174 & 35 & 161 & 36 & 171 & 25 & 215 & 19 & 213 & 17 \\
\hline & population & & & & & & & & & & \\
\hline Malta & & 14 & 34 & 15 & 33 & 15 & 18 & $\underline{12}$ & 16 & 18 & 15 \\
\hline & capita & 32 & 80 & 35 & 77 & 35 & 42 & $\overline{27}$ & 37 & $\overline{42}$ & 34 \\
\hline & population & & & & & & & & & & \\
\hline Netherlands & losses & 11309 & 1181 & 11338 & 1151 & 11191 & 945 & 11312 & 850 & 11827 & 971 \\
\hline & apita & 681 & 71 & 678 & 69 & 662 & 56 & 666 & 50 & 693 & 57 \\
\hline & population & & & & & & & & & & \\
\hline Poland & lo & 4961 & 5813 & 4495 & 5660 & 2825 & 3040 & 2788 & 2967 & 2329 & 2671 \\
\hline & Losses/capita & 130 & 152 & 118 & 148 & 74 & 80 & 73 & 78 & 61 & 70 \\
\hline & population & & & & & & & & & & \\
\hline Portugal & & 223 & 985 & 177 & 1004 & 160 & 576 & 209 & 601 & 345 & 534 \\
\hline & pita & & 93 & 17 & 95 & 15 & 55 & 20 & 58 & 34 & 52 \\
\hline & population & & & & & & & & & & \\
\hline Romania & losses & 1006 & 1378 & 978 & 1121 & 1048 & 856 & 849 & 768 & 1074 & 731 \\
\hline & pita & & 63 & & 52 & 52 & 43 & 43 & 39 & 55 & 37 \\
\hline & population & & & & & & & & & & \\
\hline Slovakia & losses & 460 & 331 & 374 & 335 & 465 & 247 & 452 & 223 & 436 & 267 \\
\hline & Losses/ & & 61 & & 62 & 86 & 45 & 83 & 41 & 80 & 49 \\
\hline & non & & & & & & & & & & \\
\hline Slovenia & & 136 & 417 & 188 & 399 & 207 & 219 & 207 & 218 & 185 & 257 \\
\hline & Losses/capita & & 203 & 91 & 193 & 100 & 106 & 100 & 105 & 89 & 124 \\
\hline & population & & & & & & & & & & \\
\hline Spain & es & 5276 & 5162 & 3938 & 4797 & 3602 & 3489 & 4336 & 3617 & 4701 & 3517 \\
\hline & Losses/capita & 114 & 112 & & 103 & 77 & 75 & 93 & 78 & 101 & 75 \\
\hline & population & & & & & & & & & & \\
\hline Sweden & 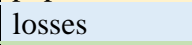 & 1570 & 609 & 1598 & 664 & 1595 & 433 & 1619 & 432 & 1567 & 288 \\
\hline & Losses/capita & 167 & 65 & 168 & 70 & 165 & 45 & 165 & 44 & 157 & 29 \\
\hline & population & & & & & & & & & & \\
\hline Unitec & & 8136 & 2321 & 8643 & 2204 & 9823 & 1726 & 10104 & 1414 & 10704 & 1482 \\
\hline & Losses/capita & 131 & 37 & 137 & 35 & 150 & 26 & 152 & 21 & 159 & 22 \\
\hline & population & & & & & & & & 621 & 513 & \\
\hline EU 28 & losses & 75830 & 45336 & 73790 & 44118 & 75420 & 30303 & 80680 & 29587 & 85310 & 29851 \\
\hline & Losses/capita & 150 & 90 & 145 & 87 & 149 & 60 & 158 & 58 & 166 & 58 \\
\hline
\end{tabular}

Source: Compiled by the author

Note: (TCCW: EUROSTAT W091+092 in 1000 tonnes, population in 1000 persons, FSCL: FAOSTAT waste or loss with element code 5123 and flag $S$ in 1000 tonnes, losses/capita in $\mathrm{kg} /$ capita)

The same result was published by Caldera et al. If we summarize from table 1 of their publication the data for 2012, Germany, we will get $(0.65+1.30+2.63+7.79=) 12.35 \mathrm{Mt}$, vs. $12658 \mathrm{kt}$, as written in Table 1 in this paper (Caldeira, De Laurentiis, Ghose, Corrado, \& Sala, 2021). 


\subsection{Correlation between TCCW and FSCL}

A correlation matrix analysis with $\mathrm{R}$ x64 4.0.4. was carried out to confirm the statement about the difference between TCCW and FSCL. The results are given in Figure 2.

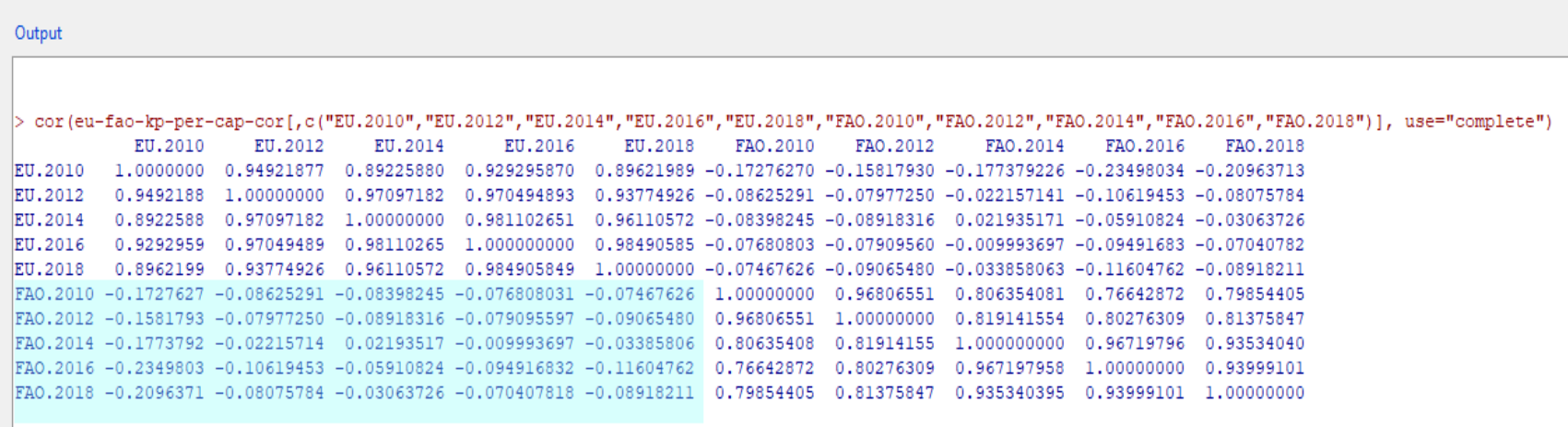

Figure 2. The Results of the Correlation Matrix Analysis with R X64 4.0.4, on Kg/Cap/Year Data from Table 1

Source: Compiled by the author

All correlations are negative (except from 1 out of 25 ), and the biggest correlation is -0.23 , which means that the connection between TCCL and FSCL is inverse and very weak.

\subsection{Trends}

Trendlines were created after calculating correlation, as given in Figure. 3.

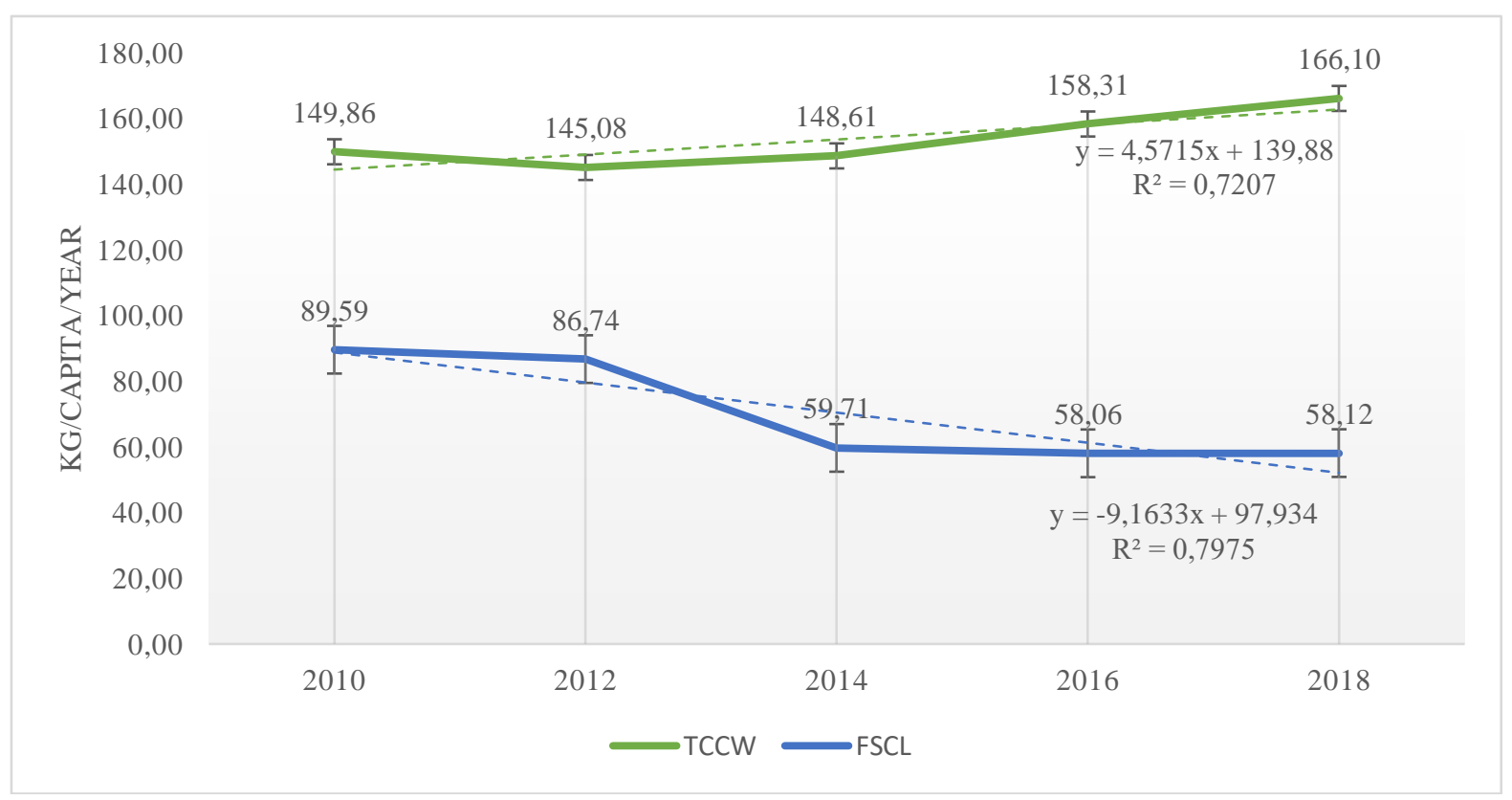

Figure 3. TCCL and FSCL in the EU28, from 2010 till 2018

Source: Compiled by the author

We can see two different trends, increasing and decreasing in Figure 3. It may be explained mainly by household wastes, which are included in TCCW but not in FSCL. The next step was the t-test of decreasing and increasing with R x64 4.0.4., as given in Figure 4. 


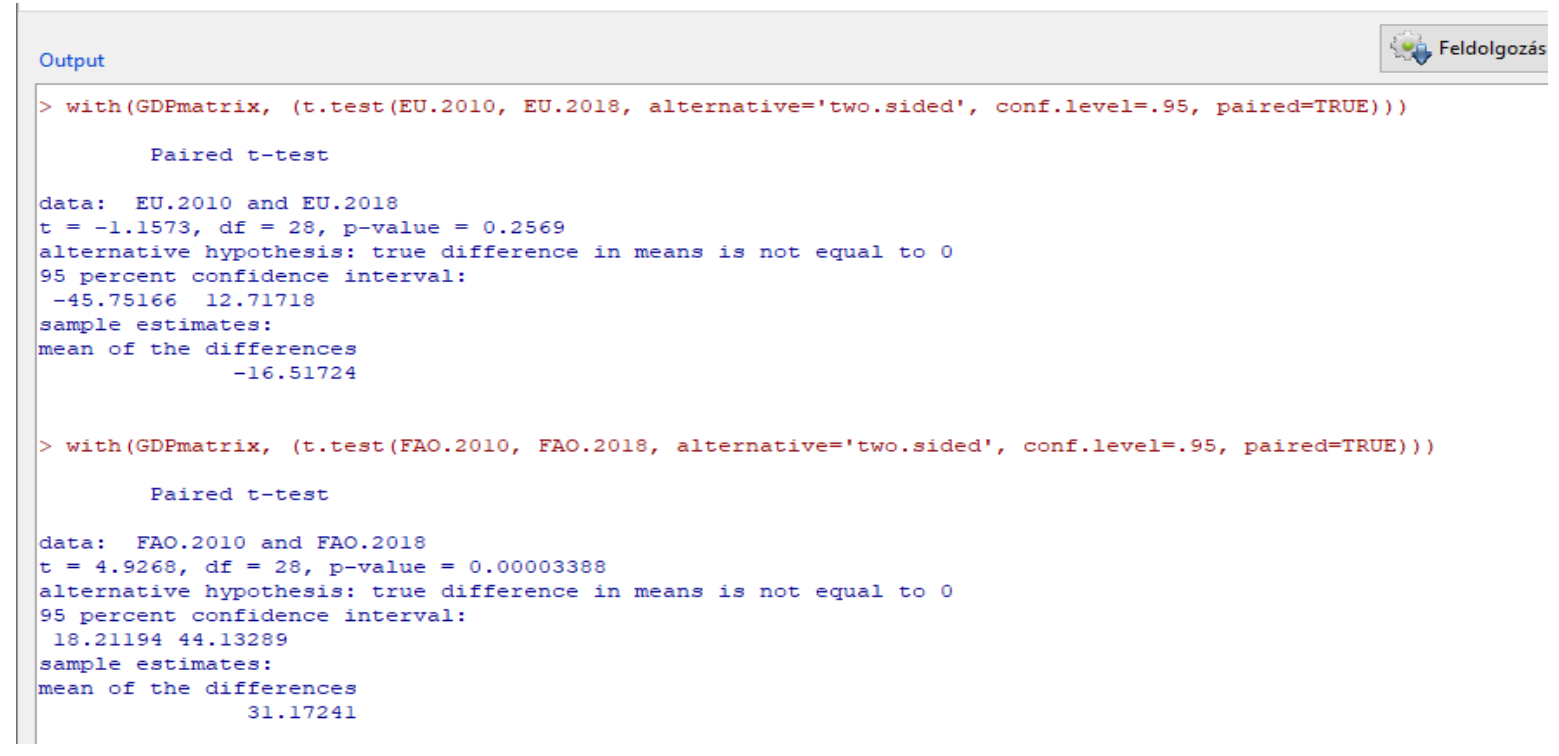

Figure 4. Results of the Paired t-test

Source: Compiled by the author

The results given in Figure 4 show that the increase of TCCW is not significant and the decrease of FCCL is significant on $95 \%$ level.

\subsection{Correlations with Other Indexes}

The correlation with different indexes was evaluated in similar research when the performance of different countries was investigated, as Grekousis et al. had done (Grekousis, Mountrakis, \& Kavouras, 2017). GDP alternatives are well described in the research of Szigeti et al. (Szigeti, Tóth, Borzán, \& Farkas, 2014). The correlation was calculated with two indexes, the real GDP per capita (the results of the production activity in euros per inhabitant) and the Human Development Index (HDI), retrieved from the UN Development Programme. It is a summary measure that considers the health conditions through life expectancy at birth (Index Life), educational attainment through means and expected years of schooling (Index Education), and the general economic status through the gross national income (GNI) per capita (Index Income). Real GDP per capita was downloaded from EUROSTAT and HDI from the UN Human Development Reports (http://hdr.undp.org/en/indicators/137506\#) 26.04.212. The results of the correlation of the GDP with TCCW and FSCL are given in Figure 5.

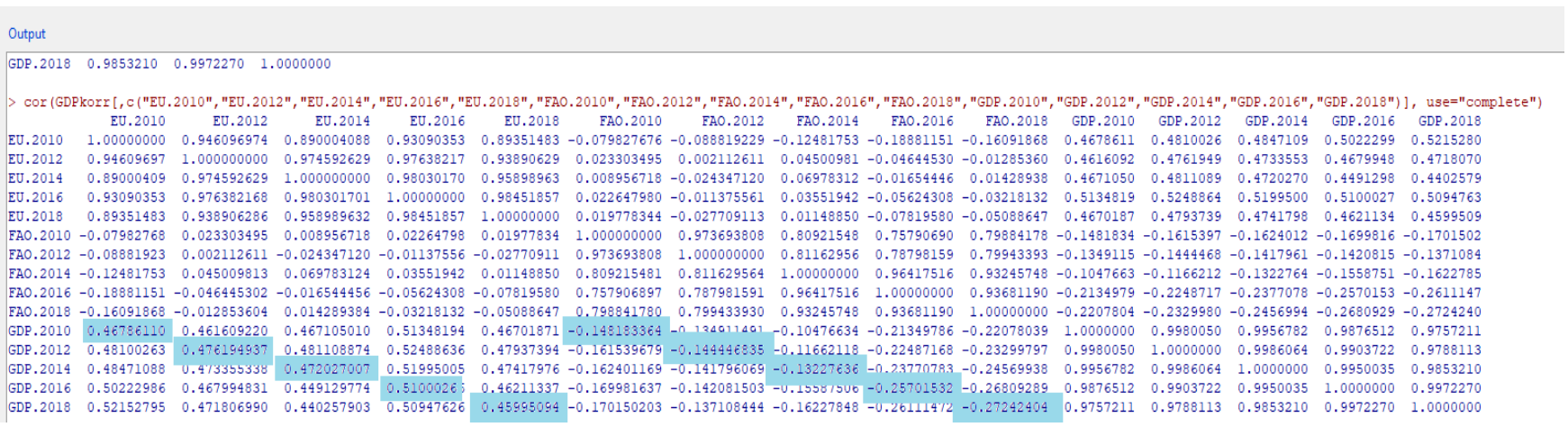

Figure 5. The Results of the Correlation of Real GDP, $€$ per capita with FSCL and TCCW in kg per capita Source: Compiled by the author

There is a moderate positive correlation between GDP and TCCW $(r=0.46-0.51)$, and a very weak inverse correlation ( $\mathrm{r}=-0.14--0.27)$ in the case of the GDP and FSCL. The results of the correlation of HDI with FSCL and TCCW are given in Figure 6. 


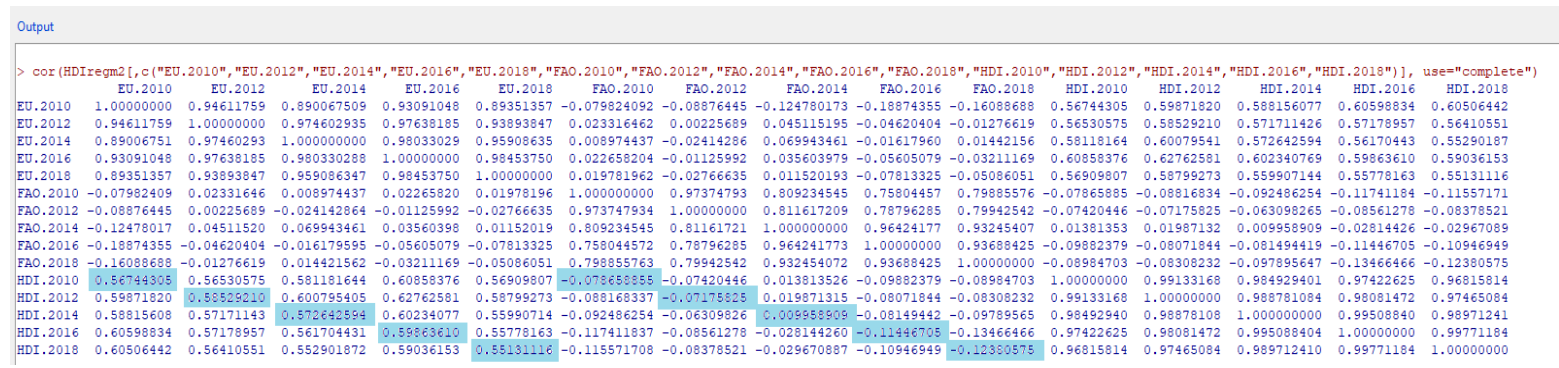

Figure 6. The Results of the Correlation of HDI with FSCL and TCCW

Source: Compiled by the author

There is a moderate positive correlation between HDI and TCCW ( $\mathrm{r}=0.55-0.59)$, and a weak correlation near zero $(r=-0.01-0.12)$ in the case of HDI and FSCL, which may be evaluated as "no correlation". It is concluded that the correlation between the HDI and TCCW is higher $(\mathrm{r}=0.55-0.59)$, than between the GDP and TCCW $(r=0.46-0.51)$, and it is a moderate positive correlation. The correlation between the HDI and FSCL is higher and is negative, $(r=-0.14--0.24)$, but very weak. The correlation between the GDP and FSCL are so near zero $(\mathrm{r}=-0.01-0.12)$ that no correlation may be said.

\subsection{Calculation of the Food Waste Loss Trend Index (FWLTI)}

We see in Table 1 that not all member states follow the trends of the average values of the EU. To compare trends in the EU28 member states, a new index was generated, the so-called Food Waste Loss Trend Index (FWLTI). Trendlines were calculated for each member state. An index (FWLTI) was created to describe each country. This index is the coefficient of $\mathrm{x}$ from each formula of the linear trendline. So, each member state of the EU28 is characterised by two numbers - from the FSCL and TCCW trendline formula. These indexes show the weight and the direction of the FWL generation changes. Indexes, (FWLTI) derived from the trendlines are given in table 2. (Column A - without marking, Column B - value marked green below zero, red above zero, Column $\mathrm{C}$ - value marked green below the EU28 average, red above the EU28 average.)

Table 2. FWLTI Indexes of FWL Trends in the EU28 (edited by author)

\begin{tabular}{|c|c|c|c|c|c|c|}
\hline & \multicolumn{2}{|c|}{$\mathbf{A}$} & \multicolumn{2}{|c|}{ B } & \multicolumn{2}{|c|}{$\mathbf{C}$} \\
\hline Member State & TCCW & FSCL & TCCW & FSCL & TCCW & FSCL \\
\hline Austria & 19,46 & $-8,30$ & 19,46 & $-8,30$ & 19,46 & $-8,30$ \\
\hline Belgium & 79,34 & $-18,93$ & 79,34 & $-18,93$ & 79,34 & $-18,93$ \\
\hline Bulgaria & 2,54 & $-34,52$ & 2,54 & $-34,52$ & 2,54 & $-34,52$ \\
\hline Croatia & 2,72 & 5,93 & 2,72 & 5,93 & 2,72 & 5,93 \\
\hline Cyprus & $-0,62$ & 1,49 & $-0,62$ & 1,49 & $-0,62$ & 1,49 \\
\hline Czech Republic & 9,93 & 2,13 & 9,93 & 2,13 & 9,93 & 2,13 \\
\hline Denmark & 15,16 & $-27,11$ & 15,16 & $-27,11$ & 15,16 & $-27,11$ \\
\hline Estonia & $-10,03$ & $-0,46$ & $-10,03$ & $-0,46$ & $-10,03$ & $-0,46$ \\
\hline Finland & 5,54 & 11,04 & 5,54 & 11,04 & 5,54 & 11,04 \\
\hline France & 5,40 & $-3,01$ & 5,40 & $-3,01$ & 5,40 & $-3,01$ \\
\hline Germany & 7,78 & $-7,91$ & 7,78 & $-7,91$ & 7,78 & $-7,91$ \\
\hline Greece & 12,41 & $-19,49$ & 12,41 & $-19,49$ & 12,41 & $-19,49$ \\
\hline Hungary & $-6,36$ & $-9,46$ & $-6,36$ & $-9,46$ & $-6,36$ & $-9,46$ \\
\hline Ireland & $-35,31$ & $-15,61$ & $-35,31$ & $-15,61$ & $-35,31$ & $-15,61$ \\
\hline Italy & 1,15 & $-11,21$ & 1,15 & $-11,21$ & 1,15 & $-11,21$ \\
\hline Latvia & 11,44 & $-4,79$ & 11,44 & $-4,79$ & 11,44 & $-4,79$ \\
\hline Lithuania & 1,54 & 2,41 & 1,54 & 2,41 & 1,54 & 2,41 \\
\hline Luxembourg & 13,24 & $-5,50$ & 13,24 & $-5,50$ & 13,24 & $-5,50$ \\
\hline Malta & 1,04 & $-13,21$ & 1,04 & $-13,21$ & 1,04 & $-13,21$ \\
\hline Netherlands & 1,31 & $-4,71$ & 1,31 & $-4,71$ & 1,31 & $-4,71$ \\
\hline Poland & $-18,11$ & $-23,35$ & $-18,11$ & $-23,35$ & $-18,11$ & $-23,35$ \\
\hline Portugal & 2,87 & $-11,84$ & 2,87 & $-11,84$ & 2,87 & $-11,84$ \\
\hline Romania & 1,60 & $-6,39$ & 1,60 & $-6,39$ & 1,60 & $-6,39$ \\
\hline Slovakia & 0,50 & $-4,45$ & 0,50 & $-4,45$ & 0,50 & $-4,45$ \\
\hline Slovenia & 5,39 & $-24,65$ & 5,39 & $-24,65$ & 5,39 & $-24,65$ \\
\hline Spain & $-1,84$ & $-9,79$ & $-1,84$ & $-9,79$ & $-1,84$ & $-9,79$ \\
\hline Sweden & $-2,39$ & $-9,80$ & $-2,39$ & $-9,80$ & $-2,39$ & $-9,80$ \\
\hline United Kingdom & 7,30 & $-4,40$ & 7,30 & $-4,40$ & 7,30 & $-4,40$ \\
\hline EU28 & 4,57 & $-9,16$ & 4,57 & $-9,16$ & $\mathbf{4 , 5 7}$ & $-9,16$ \\
\hline \multirow{2}{*}{ Trend remark: } & \multirow{2}{*}{\multicolumn{2}{|c|}{ No }} & \multicolumn{2}{|c|}{ Green: decreasing } & \multicolumn{2}{|c|}{ Above EU28 average } \\
\hline & & & \multicolumn{2}{|c|}{ Red: increasing } & \multicolumn{2}{|c|}{ Under EU28 average } \\
\hline
\end{tabular}

Source: Compiled by the author 
Another index is available in scientific literature to describe changes in FWL generation, too. The first example is the Food Loss Percentage (FLP) and the Food Loss Index (FLI), defined by Fabi et al. and proposed by FAO (Fabi \& English, 2019). FLP and FLI are suggested as an indicator of SDG12.3 and not as a tool kit to evaluate policies and management. The second example is published in the FOOD WASTE INDEX REPORT 2021 by UNEP, where the Food Waste Index (FWI) is used as an indicator to achieve SDG12.3. Moreover, it was created compared to FWL in the subject year to the baseline year and is expressed in percentages (Hamish Forbes, Tom Quested, 2021). These indexes do not show trends; they only represent the result of decrease till the investigated subject year.

This difference makes FWLTI more useful than other indexes. If the only start and end year is considered in EU28, the FSCL decreases from $89.59 \mathrm{~kg} /$ capita (2010) to $58.12 \mathrm{~kg} / \mathrm{capita}$ (2018), as written in Table 1 and shown in Figure 3. It means, FSCL decreased to $64.8 \%$. In this case the trendline is $y=-7.8688 \mathrm{x}+97.463\left(\mathrm{R}^{2}=1\right)$. If all four data is accounted, the trendline is: $\mathrm{y}=-9.1633 \mathrm{x}+97.934\left(\mathrm{R}^{2}=0,7975\right)$. So, the FWLTI is much more exact - and useful for scientific purposes - as other indexes mentioned before. So, the work was continued with the usage of FWLTI. Countries were grouped into clusters with the Ward method in R x64 4.0.4. The dendrogram is given in figure.

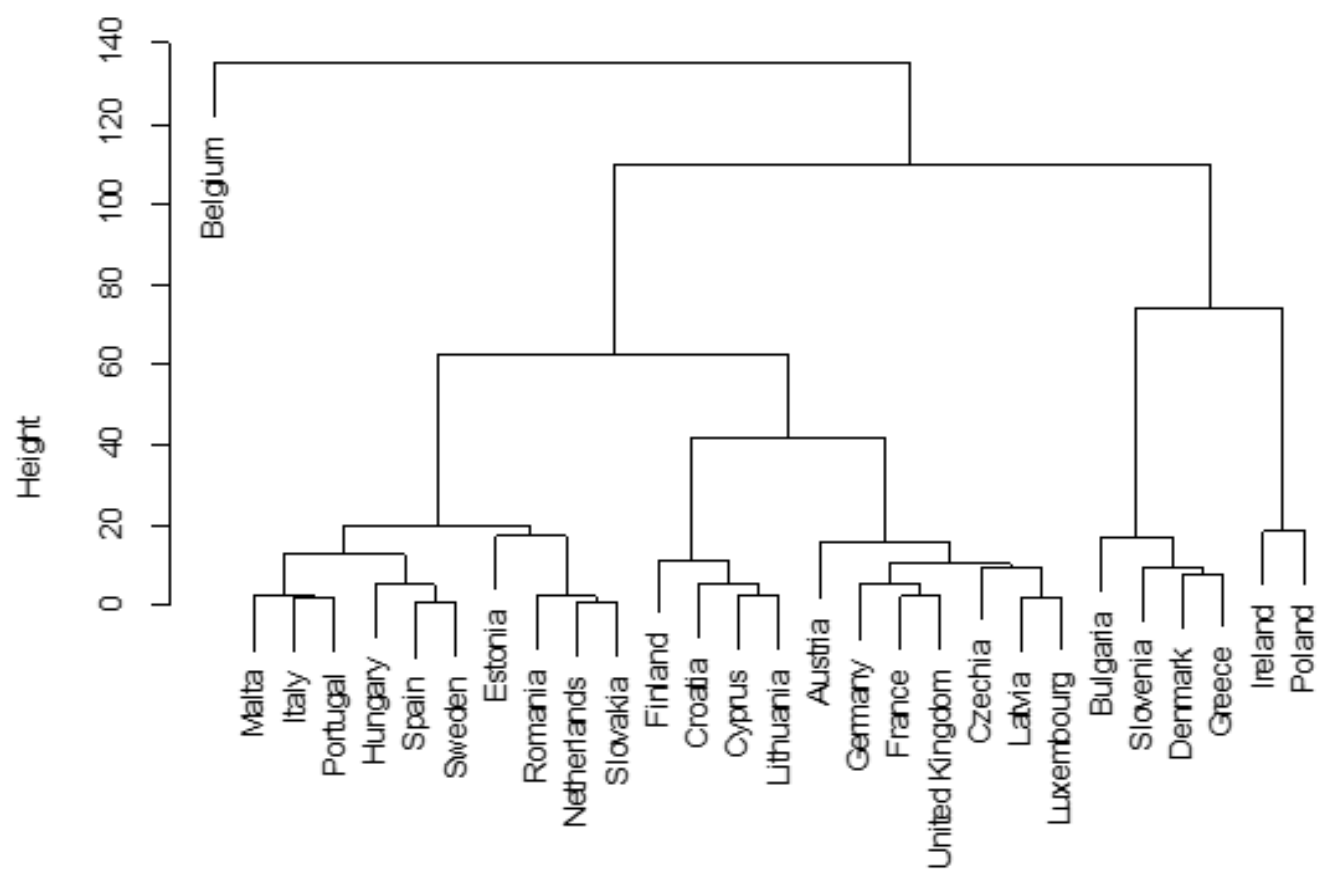

Figure 7. Cluster Dendrogram of the EU28 Member States FWLTI Indexes

Source: Compiled by the author

No common characteristics were identified among the clusters. So, the next step was to create the scatterplot, shown in Figure 8. 


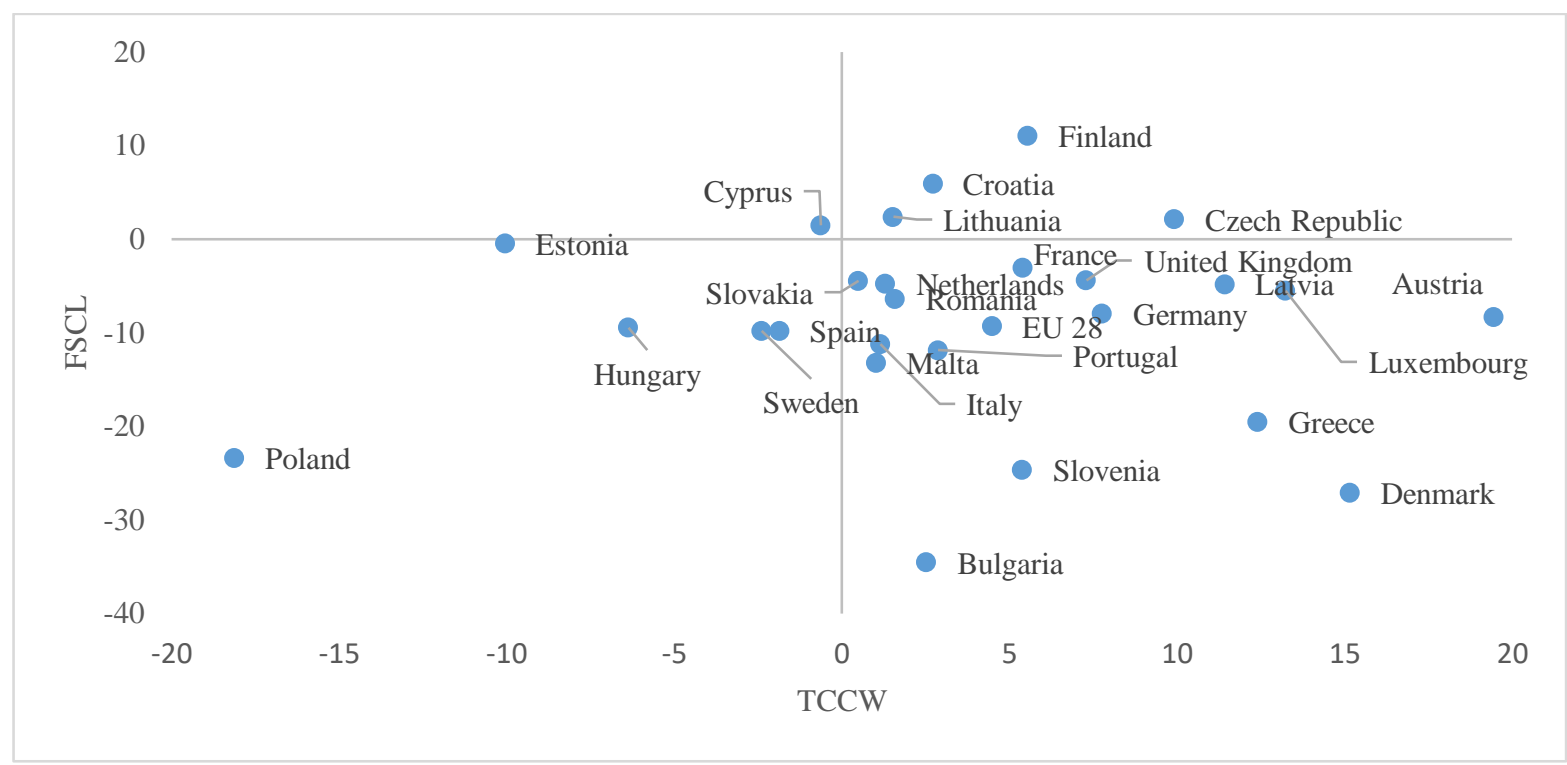

Figure 8. The Scatterplot of the EU28 Member States FWLTI - Increasing/Decreasing

Source: Compiled by the author

We can see in Figure 8 in the top-right quarter countries where the trend of FWL generation is increasing by TCCW and FSCL, too. Countries in the bottom right quarter, where FWL generation is growing by TCCW and decreasing by FSCL. We can see countries where the FWL generation is reducing by TCCW on the left side, similarly.

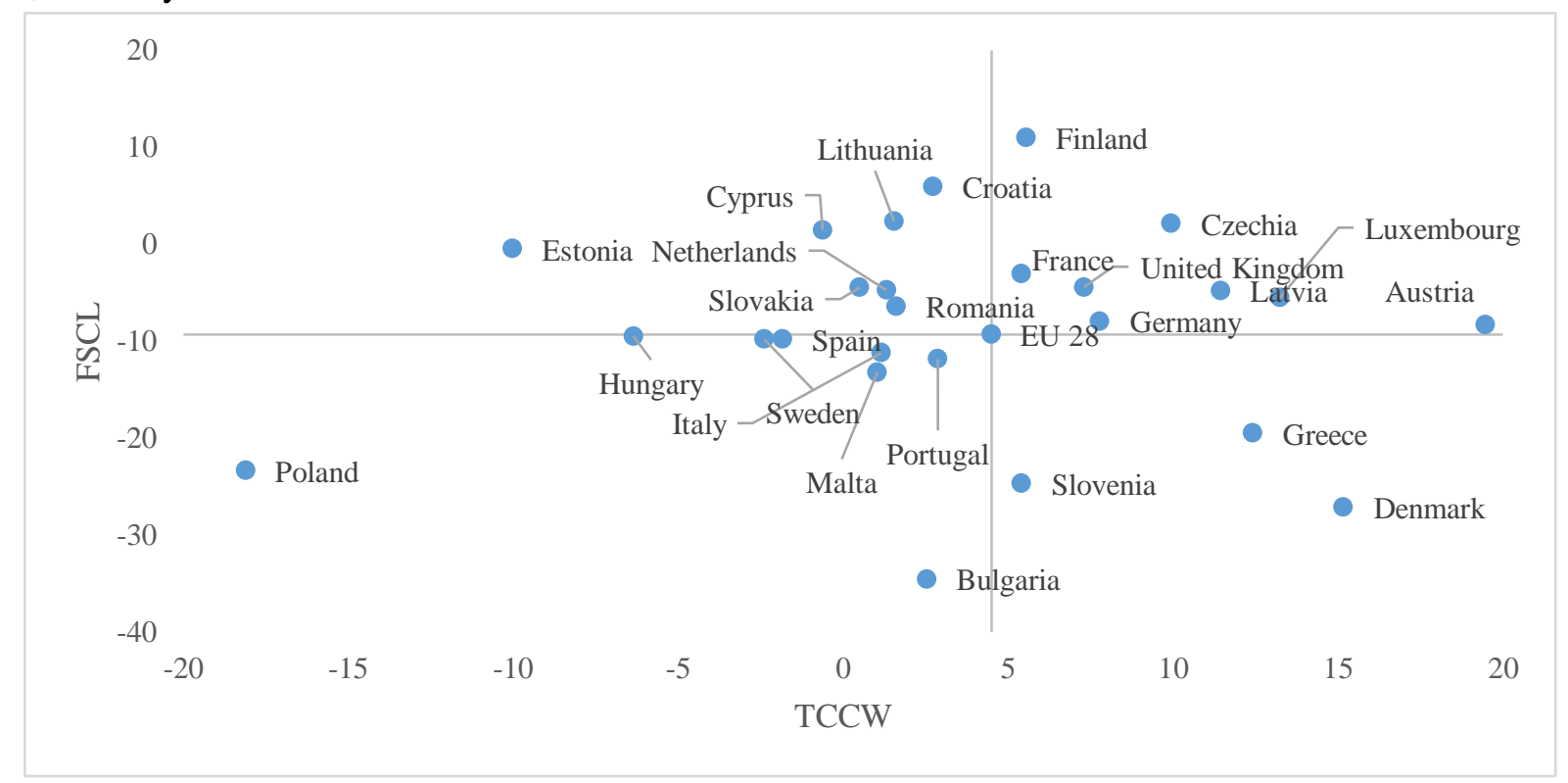

Figure 9. The Scatterplot of the EU28 Member States FWLTI Indexes - more/less as the EU28 Average

Source: Compiled by the author

Figure 9 shows the same data as figure 8, the only difference is that the cross of axes is in the point of the EU28 average.

\section{Results and Conclusion}

A big inconsistency of the FWL data in the EU28 was found in the literature investigation (Stenmarck et al., 2016). The main reason of inconsistency is the difference in definitions (Cristóbal et al., 2018), (Kasza et al., 2019), (Bräutigam et al., 2014), (Hartikainen et al., 2018), (Thyberg \& Tonjes, 2016) and (Chaboud \& Daviron, 2017). The most frequently used definitions (FAO, EU, WRAP, FUSION, and EPA) were reviewed and compared in chapter 2.2 and visualized in figure 1. Additionally, definitions from non-scientific sources (standards and BAT), were mentioned, too. It seems a new standard (maybe only on FWL) can close/fill the gap in definitions. This solution may be optimal or the best, but it seems it may not be perfect because the gap is too deep. We 
can conclude that we have so many different definitions for FWL because of the difference in the purpose of data collecting. The most justified definition - often newly created - is used in each case.

Data, downloaded from EUROSTAT and FAOSTAT are thoroughly described in chapter 2.3. The calculation was started by computing FWL per capita. Results are given in table 1. and they are in harmony with the findings of other researchers (Caldeira et al., 2021). The FSCL and TCCW are not comparable, they must be evaluated separately, it was concluded based on the difference in the data collecting methods. This difference verifies that FSCL + waste in households will not equal to TCCW. This statement was approved with a correlation matrix in chapter 2.4. All correlations are negative (except 1 from 25), and the biggest correlation is -0.23 , which means, that the connection between TCCW and FSCL is inverse and very weak, as we can see in figure 2. Two different trends can be seen in figure 3, increasing, $y=4.5715 x+139.88\left(R^{2}=0,7207\right)$ in the case of the TCCW and decreasing $y=-9.16335 x+97.934\left(R^{2}=0,7975\right)$ in the case of FSCL. This difference in the direction of trends may be explained by the difference of the FWL definition used by EUROSTAT and FAOSTAT, as TCCW include household wastes, and FSCL not, they are only mass flow data. It was particularly described in chapter 2.1 .

The difference between the data from the years 2010 and 2018 was tested with a paired t-test. The results are given in Figure 4. After evaluating these results, we can conclude that the increase of TCCW was not significant on level 95\%, but the decrease of FSCL was significant on 95\% level. It can be explained by the difference in FWL definitions, used by EUROSTAT and FAOSTAT, as it was done in this paper at the evaluation of trends. The correlation of FWL was calculated with two indexes. The first index is the most frequently used one in mainstream economy, GDP. The other index was selected from indexes, used in alternative economy, HDI. Results are in Figures 5 and 6. It is concluded that the correlation between the HDI and TCCW is higher $(r=0.55-0.59)$, than between the GDP and FSCL data $(r=0.46-0.51)$, and it is a moderate positive correlation. The correlation between the HDI and FSCL is higher and negative $(r=-0.14--0.24)$ but very weak. The correlation between the GDP and TCCW is so near zero $(r=-0.01-0.12)$ that no correlation may be said. The higher correlation between the TCCW and HDI, as in the case of GDP, may be explained by the education component of HDI, but it requires further investigation. The very weak correlations in FSCL, as it is in the material flow data, may be balanced on the technological level in the EU28 member states, but it could only be concluded after further research.

We can see FWL data in Table 1. The differences in trends of FWL in all member states are well expressed. The statistical evaluation of these differences in trends was carried out with newly generated indexes, the Food Waste Loss Trend Index (FWLTI), which could not be found in scientific literature yet. As written in chapter 2.7, The FWLTI is the coefficient of $\mathrm{x}$ from each formula of the linear trendline. So, each member state of the EU28 is characterised by two numbers - from FSCL and TCCW trendline formula. FWLTI shows the weight and the direction of FWL generation changes, and they are given in Table 2. The adequate indexes for comparison are the Food Loss Percentage (FLP) and the Food Loss Index (FLI), described by Fabi et al. and proposed by FAO (Fabi \& English, 2019). These indexes, and a third one, Food Waste Index (FWI), were used by the United Nations Environment Programme (UNEP) for the reporting of food waste in 2021 (Hamish Forbes, Tom Quested, 2021). The main difference between FLI, FLP, FWI and the index calculated in this paper (FWLTI) is that previous indexes don't show trends, only express the results of reduction till the investigated subject year.

The adequate indexes for comparison are the Food Loss Percentage (FLP) and the Food Loss Index (FLI), described by Fabi et al. and proposed by FAO (Fabi \& English, 2019). These indexes, and a third one, Food Waste Index (FWI), were used by the United Nations Environment Programme (UNEP) for the reporting of food waste in 2021 (Hamish Forbes, Tom Quested, 2021). The main difference between FLI, FLP, FWI and the index calculated in this paper (FWLTI) is that previous indexes do not show trends, only express the results of reduction till the investigated subject year. This difference makes FWLTI more useful than other indexes because the trendline, calculated from time series much more exact - and useful for scientific purposes - as other indexes, calculated only from two values, as mentioned before.

Several researchers criticized the FLI, mainly for its quantitative character (Koestler, U., Galaktionova, E., 2021), (Tayyib \& Golini, 2016), (Nicastro, Carillo, Lange, \& Schmidt, 2021). FLI authors continue to improve their indexes (Mingione, Fabi, \& Lasinio, 2021). The FLI is a good index for reporting, but for scientific purposes, the FWLTI is much more accurate because this index was calculated from natural quantities (kg/capita/year). It is not a ratio. IN THIS PARAGRAPH, the UNEP report cited above writes some criticism to FLI and FLP, which is why the third index is created, FWI. This Food Waste Index (FWI) measures the total food waste (rather than specific commodities). For this reason, the three sectors covered by the Food Waste Index are 
Food retail, Households, and Food service (Hamish Forbes, Tom Quested, 2021). But, as it is written above, these indexes do not show trends, only express the results of decrease till the investigated subject year.

The EU28 member states were clustered by FWLTI, as it is shown in Figure 7 at first. No common characteristics could be identified among the clusters on any level. To check this statement, indexes were visualised on the scatterplot two times. In the first case, the cross of axes was at zero, in Figure 8 . The cross of axes is at the average of the EU28 in Figure 9. There was no connection was found among the EU28 member states. We can conclude that every member state is an individual case; there are no standard rules for FLW generation. Perhaps, this statement is questionable for other researchers, so this work will continue to search for correlations of our FWLTI with a lot of indexes, markers, natural volumes, categories, etc. As each country is an individual case, the FWLTI is usable to evaluate efforts for lowering wastes. This evaluation helps leadership improve policies to reduce food wastes, so it helps to achieve SDGs.

Funding. There is no funding for this research.

\section{References}

1. Bellemare, M.F., Çakir, M., Peterson, H.H., Novak, L., \& Rudi, J. (2017). On the Measurement of Food Waste. American Journal of Agricultural Economics, 99(5), 1148-1158. [Google Scholar] [CrossRef]

2. Blakeney, M. (2019). Food loss and food waste: Causes and solutions. Rome: FAO. 224 p. [Google Scholar] [CrossRef]

3. Bräutigam, K.R., Jörissen, J., \& Priefer, C. (2014). The extent of food waste generation across EU-27: Different calculation methods and the reliability of their results. Waste Management and Research, 32(8), 683-694. [Google Scholar] [CrossRef]

4. Caldeira, C., De Laurentiis, V., Ghose, A., Corrado, S., \& Sala, S. (2021). Grown and thrown: Exploring approaches to estimate food waste in EU countries. Resources, Conservation and Recycling, 168, 105426. [Google Scholar] [CrossRef]

5. Chaboud, G., \& Daviron, B. (2017). Food losses and waste: Navigating the inconsistencies. Global Food Security, 12, 1-7. [Google Scholar] [CrossRef]

6. Corrado, S., \& Sala, S. (2018). Food waste accounting along global and European food supply chains: State of the art and outlook. Waste Management, 79, 120-131. [Google Scholar] [CrossRef]

7. Cristóbal, J., Castellani, V., Manfredi, S., \& Sala, S. (2018). Prioritizing and optimizing sustainable measures for food waste prevention and management. Waste Management, 72, 3-16. [Google Scholar] [CrossRef]

8. European Comission (2015). CE Action Plan. Available at: [Link]

9. European Comission (2019). Commission Implementing Decision (EU) 2019/2000 of 28 November 2019 laying down a format for reporting of data on food waste and for submission of the quality check report in accordance with Directive 2008/98/EC of the European Parliament and of the Counc. Available at: [Link]

10.European Comission (2020). Circular economy action plan (new). Available at: [Link]

11.European Parliament (2002). Regulation (EC) No 2150/2002 of the European Parliament and of the Council of 25 November 2002 on waste statistics. Available at: [Link]

12.European Parliament (2008). Directive 2008/98/EC of the European Parliament and of the Council of 19 November 2008 on waste and repealing certain Directives. Available at: [Link]

13.EUROSTAT (2010). Guidance on classification of waste according to EWC-Stat categories Supplement to the Manual for the Implement. Available at: [Link]

14.Fabi, C., \& English, A. (2019). Methodological proposal for monitoring sdg target 12.3. Sub-indicator 12.3.1.a The food loss index design, data collection methods and challenges. Rome. Available at: [Link]

15.FAO (n.d.). New Food Balances Description of utilization variables. Available at: [Link]

16.Fujii, H., \& Kondo, Y. (2018). Decomposition analysis of food waste management with explicit consideration of priority of alternative management options and its application to the Japanese food industry from 2008 to 2015. Journal of Cleaner Production, 188, 568-574. [Google Scholar] [CrossRef]

17.Gelman, A., \& Hill, J. (2008). Data Analysis Using Regression and Multilevel/Hierarchical Models. Available at: [Link]

18.Grekousis, G., Mountrakis, G., \& Kavouras, M. (2017). MODIS-derived forest and cropland land cover 2011 estimations to socioeconomic and environmental indicators for the European Union's 28 countries. GIScience \& Remote Sensing Linking, 53(1), 122-146. [CrossRef]

19.Hamish Forbes, Tom Quested, C.O. (2021). FOOD WASTE INDEX REPORT 2021. Nairobi: United Nations Environment Programme. Available at: [Link]

20.Hanson, C., Lipinski, B., Robertson, K., Dias, D., Gavilan, I., Gréverath, P., Quested, T. (2016). Food Loss 
and Waste Accounting and Reporting Standard V E R S I O N 1.0 FLW Protocol Steering Committee and Authors Other Contributing Authors. World Resources Institute. 156 p. Available at: [Link]

21.Hartikainen, H., Mogensen, L., Svanes, E., \& Franke, U. (2018). Food waste quantification in primary production - The Nordic countries as a case study. Waste Management, 71, 502-511. [Google Scholar] [CrossRef]

22.Irani, Z., Sharif, A. M., Lee, H., Aktas, E., Topaloğlu, Z., van’t Wout, T., \& Huda, S. (2018). Managing food security through food waste and loss: Small data to big data. Computers and Operations Research, 98, 367-383. [Google Scholar] [CrossRef]

23.Kasza, G., Szabó-Bódi, B., Lakner, Z., \& Izsó, T. (2019). Balancing the desire to decrease food waste with requirements of food safety. Trends in Food Science and Technology, 84(June 2017), 74-76. [Google Scholar] [CrossRef]

24.Kinnaman, T.G. (2006). Policy watch examining the justification for residential recycling. Journal of Economic Perspectives, 20(4), 219-232. [Google Scholar] [CrossRef]

25.Koestler, U., Galaktionova, E. (2021). FAO Food Loss Index methodology and policy implications. Studies in Agricultural Economics, 123(1), 1-7. [Google Scholar] [CrossRef]

26.Mingione, M., Fabi, C., \& Lasinio, G.J. (2021). Measuring and Modeling Food Losses. Journal of Official Statistics, 37(1), 171-211. [Google Scholar] [CrossRef]

27.Nicastro, R., Carillo, P., Lange, S., \& Schmidt, T. (2021). Sustainability Food Loss and Waste Prevention Strategies from Farm to Fork. Sustainability, 13(10), 5443. [Google Scholar] [CrossRef]

28.Radauer, A. (2020). Driving from the fringe into spotlight. The underrated role of standards and standardisation in RTDI policy and evaluation. Fteval Journal for Research and Technology, 51, 59-65. [Google Scholar] [CrossRef]

29.Reutter, B., Lant, P.A., \& Lane, J.L. (2017). The challenge of characterising food waste at a national level - An Australian example. Environmental Science and Policy, 78(September), 157-166. [Google Scholar] [CrossRef]

30.Reynolds, C., Goucher, L., Quested, T., Bromley, S., Gillick, S., Wells, V.K., Jackson, P. (2019). Review: Consumption-stage food waste reduction interventions - What works and how to design better interventions. Food Policy, 83(January), 7-27. [Google Scholar] [CrossRef]

31.Schanes, K., Dobernig, K., \& Gözet, B. (2018). Food waste matters - A systematic review of household food waste practices and their policy implications. Journal of Cleaner Production, 182, 978-991. [Google Scholar] [CrossRef]

32.Stenmarck, A., Jensen, C., Quested, T., Moates, G., Buksti, M., Cseh, B., Östergren, K. (2016). Estimates of European food waste levels. Reducing food waste through social innovation. Fusions. Available at: [Link]

33.Szigeti, C., Tóth, G., Borzán, A., \& Farkas, S. (2014). GDP Alternatives and their Correlations. Journal of Environmental Sustainability, 3(3), 1-12. [Google Scholar] [CrossRef]

34.Tayyib, S., \& Golini, N. (2016). The FAO approach to food loss concepts and estimation in the context of Sustainable Development Goal 12 Target 3. In Paper presented to the 17th International Conference on Agricultural Statistics (Rome, Italy: 26-28 October 2016). (p. 7). [CrossRef]

35.Thyberg, K.L., \& Tonjes, D.J. (2016). Drivers of food waste and their implications for sustainable policy development. Resources, Conservation and Recycling, 106, 110-123. [Google Scholar] [CrossRef]

36.United Nations (2015). 70/1. Transforming our world: the 2030 Agenda for Sustainable Development Transforming our world: the 2030 Agenda for Sustainable Development Preamble. Available at: [Link] 